\title{
Primary Hepatic Neuroendocrine Tumor: What Do We Know Now?
}

\author{
Benjamin Quartey ${ }^{\mathrm{a}, \mathrm{b}}$
}

\begin{abstract}
Primary hepatic neuroendocrine tumors (PHNETs) are rear neoplasm. Diagnosis is an evolution, and requires a systematic clinical exclusion with histological confirmation. Treatment is surgical with excellent prognosis, and a long-term follow-up is required due to high tumor recurring rate. Knowledge from this species of tumor remains limited due to paucity of cases. This article elaborates the key features, diagnosis algorithm, current management, other treatment options and extensive review of literature on this rear tumor.
\end{abstract}

Keywords: Primary hepatic tumor; Neuroendocrine tumor; Carcinoid; Liver

\section{Introduction}

Neuroendocrine (carcinoid) tumors (NETs) are rear heterogeneous group of neoplasm derive from neuroendocrine system first described by Oberndorfer in 1907; a German pathologist who coined the term Karzinoide to describe their carcinoma-like but benign and indolent nature [1]. Although NETs are distributed throughout the body, $54.5-75 \%$ are found in the gastrointestinal tract $[2,3]$ with $44.7 \%, 19.6 \%, 16.7 \%, 10.6 \%$ and $7.2 \%$ in the small intestines, rectum, appendix, colon and stomach respectively [3]. However, NETs makes about 1-2\% of all gastrointestinal

Manuscript accepted for publication July 5, 2011

${ }^{a}$ National Capital Consortium, National Naval Medical Center, Department of Surgery, 8901 Wisconsin Ave, Bethesda, MD 20889, USA

${ }^{\mathrm{b} C}$ Corresponding author: Benjamin Quartey.

Email: Benjamin.Quartey@med.navy.mil

doi:10.4021/wjon341w tumors [4] and the liver is the most common site of metastases $[2,3]$. Primary hepatic neuroendocrine tumors (PHNETs) are a rarity and represents about $0.3 \%$ of all neuroendocrine tumors [5].

Due to the rarity of PHNETs, diagnosis is a continuum: pre-operatively, intra-operatively, and post-operatively. Despite advances in radiographic imaging, the current technology is still inadequate in making a definite diagnosis preoperatively. Intra-operative anatomical hepatic resection is therefore the recommended treatment of choice. Post surgical recurrence is an issue, but prognosis is excellent. This review highlights the current diagnosis criteria, management, other treatment options and review of literature on PHNETs.

124 reported cases of PHNETs (this include PHNEC and PHCT) were indentified in the literature [6-76]. The mean age at diagnosis was 51.9 years (standard deviation (SD) \pm 16.5 ), and no clear gender preference exist (50.8\% female and $49.2 \%$ male). $73.3 \%$ of the cases were symptomatic and abdominal pain (65\%) was the common complaint. Most tumors were single lesions (76.3\%) with size ranging from $1.5-27 \mathrm{~cm}$, located usually on the right lobe $(48.4 \%)$ and diagnosed by histopathologic examination of the resected specimens (77.4\%). $84.5 \%$ underwent surgery with mean disease free interval of 33.6-month and 5-year survival of $75 \%$. 28.8\% died after a mean follow up of 41 months. Most tumors stained positive for chromogranin A and endocrinologically silent.

\section{Origin and Classification}

The origin of PHNETs continues to be an ongoing investigation and a mystery with three theories put forward for the past decade. These theories includes: (1) possible transformation of liver malignant stem cells [7]; (2) differentiation of ectopic heterotopic pancreatic or adrenal tissue located in the liver [8]; and (3) transformation of neuroendocrine cells in the epithelium of the intrahepatic biliary duct [78]. The biliary duct theory is the most favored and more accurate since the bile duct contain neuroendocrine argentaffin cells $[9,10]$, and the assumption that chronic inflammation in the 
biliary system can induced intestinal metaplasia leading to the development of neuroendocrine tumor [79].

NETs used to be classified based on tumor location as foregut, midgut, and hindgut NETs. This classification is complicated by the nomenclature "carcinoid" and "neuroendocrine tumors". To ensure uniform communication, the World Health Organization (WHO) in 2000 adopted the term neuroendocrine tumors to describe both neuroendocrine and carcinoid tumors. The panel also adopted three classification of neuroendocrine tumors based on tumor morphology, vascular invasion and proliferative index. These sub-types includes: well-differentiated neuroendocrine carcinoma (no local invasion or metastases: typical carcinoid); moderately differentiated neuroendocrine carcinoma (atypia, local invasion or metastases: atypical carcinoid) and poorly differentiated neuroendocrine carcinoma (highly atypical cells, lymph node or distance metastases: small cell carcinoma) [80].

Therefore, all reported cases of primary hepatic carcinoid tumors (PHCT), primary hepatic neuroendocrine tumors (PHNETs) or primary hepatic neuroendocrine carcinoma (PHNEC) are all the same entity. Unfortunately, the term carcinoid and neuroendocrine carcinoma is still being used to describe low grade malignant tumor with minimal pleomorphism and malignant epithelial neoplasm with high mitotic activity, necrosis and invasion respectively.

\section{Incidence}

Despite increase in the incidence of neuroendocrine tumor over time [2, 81], PHNETs remains a rarity, although possible [2] with less than 130 reported cases in English literature to the best of my knowledge [6-76]. This number includes both PHCT and PHNEC. However, most of the reported cases were PHCT in a form of retrospective case series and reports [6, 7, 9-13, 15-24, 26-49, 51-54, 60-68, 70-76]. The estimated incidence rate for carcinoid tumor in the United States was 6.25 cases per 100000 people per year [2, 6].

\section{Clinical Features}

PHNET usually does not present with any specific clinical features, but the common reported symptoms are due to mass effect of the liver and adjacent organ. These include vague abdominal pain, jaundice, palpable right upper quadrant mass, weight loss, and diarrhea. Abdominal pain is the most common complaint in symptomatic patients $[6,11,81$, 82 ] and $65 \%$ of the cases reviewed in this series reported this finding. Surprisingly, less than $20 \%$ of patients with PHNETs presents with classic carcinoid syndrome [11, 81, 82], described as skin flushing, abdominal pain and episodic diarrhea. $6.8 \%$ of the cases analyzed in this review had true carcinoid syndrome. Although it's unclear why PHNETs are endocrinologically silent, others attribute this to spillage of hepatic enzymatic degradation of neoplastic-derived products directly into portal circulation [12].

Among the reported cases of PHNETs, female are affected slightly more often than men (50.8\% versus $49.2 \%$ ), with a mean age of 51.9 years (range 8-89 years), and the highest incidence was in fifth decade similar to previous report [13, 81, 82]. Most tumor were solitary (76.3\%) but can be multicentric, and right lobar (48.4\%) preference exist. Extrahepatic metastasis is about $18.6 \%$ and common sites include lung, bone and brain [13].

\section{Laboratory Data}

Although PHNETs are hepatic in origin, standard serological marker such as apha-fetoprotein (AFP), carcinoembryonic antigen (CEA), and cancer-antigen (CA) 19-9 are nondiagnostic and not helpful [12]. Serum 5-hydroxytryptamine (5-HT) or 24-hour urine of 5-hydroxyindoleacetic acid (5-HIAA) may be effective but inferior to serum Chromogranin A in diagnosing NEC. Their respective sensitivity and specificity are (73\% versus $87-100 \%)$ and (90\% versus 92\%) [12]. Chromogranin A is therefore considered the most useful marker to confirm neuroendocrine tumors including neuroendocrine carcinoma and carcinoids.

\section{Diagnosis}

Since the first documented PHNET by Edmondson 53-years ago [17], diagnosis of this rear oncological entity is still a mystery. Diagnosis is a continuum starting from preoperative to post surgical including long-term follow-up in search of extra-hepatic primary.

Preoperative diagnosis of PHNETs with needle biopsy has been reported $[8,10,11,13,18,23,28,29,36,52,62$, $68,72]$, but the diagnostic accuracy is not high enough. Needle biopsy was used in several cases and confirmed with surgical resection but this technique was accurate in making diagnosis in $11.3 \%(14 / 124)$ of the cases reviewed. Hwang et al reported $57.1 \%$ (4 out 7 patients) diagnostic accuracy in their small series, however the author caution against use of this diagnostic method [23]. The low diagnostic accuracy is evident in reported cases of misdiagnosis of PHNETs as hepatocellular carcinoma or cholangiocarcinoma [18-21, 24, 34, 44, 45]. Moreover, the literature is still unclear on the value of liver biopsy therefore post-surgical histological and immunohistochemical evaluation serves as the main method for the final diagnosis.

The objectives of preoperative evaluation is to actively exclude extrahepatic primary source since NET metastases to the liver are more common than PHNETs [2, 20, 21]. This approach is a stepwise, meticulous search for extrahepatic 
lesion beginning with ultrasound, computed tomography (CT) and magnetic resonance imaging (MRI) followed by octreoscan, upper and lower gastrointestinal endoscopy and diagnostic laparotomy [22]. Nevertheless, there is $16 \%$ failure rate to locate extrahepatic carcinoid despite extensive systematic investigation [85].

A traditional ultrasound will show multiple cystic lesions or solid mass [8, 20-23, 24, 26, 29, 31, 37, 52], and although not specific, it is helpful for differential diagnosis for hepatocellular carcinoma which appears as colliquation necrosis on ultrasound [24, 25, 27, 73]. CT scan will also reveal a cystic lesion with tumor enhancement due to the tumor's hypervascularity [8, 20, 24-26, 29]. Utility of angiogram is questionable but can be helpful in elucidating the hypervascularity and central location of PHNETs [20, 21, 24, 26, 34, 44]. Hypointense and hyperintense $\mathrm{T} 1$ and $\mathrm{T} 2$-weighted images of MRI respectively are better in characterizing these lesions and currently being used more often [24-27]. However, PHNETs have a wide spectrum of appearance on MRI with benign and malignant features making preoperatively diagnosis still inaccurate [27].

PET-scanning with ${ }^{11} \mathrm{C}-5$ hydroxytryptophan tracer which concentrate highly in carcinoid tumors allowed for the identification of primary tumor in 84\% (16 of 19 patients) of the cases reported by Orlefors et al [84]. The technology is however limited to few medical centers. Among the radiographs discussed above, octreoscan scintigraphy is the most efficient and ideal with specificity of $83 \%$ [25, 85], and can detect extrahepatic lesion and recurrence [25, 85, 86]. Donadon et al reported $88 \%$ specificity, $83 \%$ accuracy and $100 \%$ positive predictive value for octreoscan in detection of PHNETs in their series [15]. For complete work up, both upper and lower endoscopy is recommended [22].

Nevertheless, there is $16 \%$ failure rate using the above preoperative modalities to locate extrahepatic primary lesions [87], making surgical resection the most commonly used method and considered the treatment of choice [6, 10, 13, 15, 81, 82]. Sometimes, a very close post surgical long-term follow-up is required for definite diagnosis of primary hepatic lesion [15].

\section{Differential Diagnosis}

The differential diagnosis is broad and the most common consideration include metastatic neuroendocrine tumor, hepatocellular carcinoma, small cell lymphocytic lymphoma, cholangiocarcinoma with neuroendocrine differentiation, metastatic Merkel cell carcinoma, and epithelioid variant of gastrointestinal stromal tumor [28 ].

\section{Pathology and Diagnosis}

Among the reported cases, PHNETs ranges from 1.5-27 cm with a mean of $9.4 \mathrm{~cm}(\mathrm{SD} \pm 5.8)$ grossly, and they are generally gray-yellow in color and well demarcated lesion with multiple irregular hemorrhagic areas, but with cystic features ocassionally [8, 9, 29]. Microscopically, the tumor shows unique finding of insular, nested, trabecular or mixed pattern of cell growth pattern [6-76]. Immunohistological analysis is the most accurate diagnostic method due to high accuracy for detecting markers such as chromgranin A (CgA), neurospecific enolase (NSE), neurilemmna cell S-100 protein and synaptophysin (SYP) [13, 28, 81, 82]. CgA was detected immunohistochemically in $94.7 \%$ of cases in this review comparable to the $84 \%$ reported by Iwao et al [13]. Therefore CgA is a sensitive index in diagnosing NEC [30, 80]. Some cases were analyzed histologically using Grimelius silver and Fontana-Masson stains [7, 9, 13, 19, 20, 24, 25, 28, 30, $31,35-37,45,47]$. These special stains can raise the diagnostic index although inferior to immunohistochemical analysis in diagnosing NECs.

\section{Surgical Management, Prognosis and Recur- rence}

The main treatment modality for PHNETs was surgical resection in $84.5 \%$ cases reviewed and the achieved 5-year survival rate was $75 \%$. Knox et al reported 78\%, 5-year survival rate in their 48 patient series [6] comparable to the 5-year, $74 \%$ survival rate reported by Iwo et al from the analysis of 53 patients with PHNETs [13]. The recurrence rate for both series was $18 \%$ comparable to the $19.8 \%$ reported in this series. Hwang et al linked the recurrence or prognosis of PHNETs to Ki67 (marker of tumor proliferation) index of $<2 \%$ [18]. In their report, Ki67 was a prognostic factor for tumor recurrence, with a mean value in the non-recurrent group of $1.7 \%$ [18]. The longest disease-free time interval was 180 months [30] with a mean of 33.6 months.

Moreover, aggressive and major hepatic resection for HNETs is safe but the extent of the disease and type of surgery does not influence the survival rate [29]. The literature is limited with regards to extent of PHNETs burden and surgical resection and their influence on survival. Knox et al reported a comparable survival for patients with uni-lobar disease and bi-lobar disease, although the 10 year survivals were $88 \%$ and $47 \%$ respectively [6]. The extrahepatic involvement such as bone, lymph node and lung in their series was $60 \%, 60 \%$ and $40 \%$ respectively [6]. As shown in Table 1, the collective (bone, lung, lymph node) extrahepatic involvement was $18.6 \%$. Metachronous lymph node metastasis is a major concerned with PHNETs but this can be managed with lymphadenectomy with good results [21]. Overall, surgical resection is effective, safe and prognosis is excellent despite high recurrence rate. 
Table 1. Characteristics of 124 Cases of PHNETs

\begin{tabular}{|c|c|}
\hline Characteristics & $\mathrm{N}^{*}(\%)$ \\
\hline \multicolumn{2}{|l|}{ Age(years) } \\
\hline Range & 8-89 \\
\hline Mean & $51.9 \pm 16.5$ \\
\hline \multicolumn{2}{|l|}{ Gender } \\
\hline Male & $61 / 124(49.2 \%)$ \\
\hline Female & 63/124 (50.8\%) \\
\hline \multicolumn{2}{|l|}{ Presentation } \\
\hline Symptomatic & 88/120 (73.3\%) \\
\hline Abdominal Pain & $57 / 88(65.0 \%)$ \\
\hline Abdominal Mass & $11 / 88(12.5 \%)$ \\
\hline Jaundice & $4 / 88(45.0 \%)$ \\
\hline Classic carcinoid syndrome & $6 / 88(6.8 \%)$ \\
\hline Asymptomatic & $32 / 120(26.7 \%)$ \\
\hline \multicolumn{2}{|l|}{ Method of diagnosis } \\
\hline Surgery & $94 / 124(77.4 \%)$ \\
\hline Biopsy & $14 / 124(11.3 \%)$ \\
\hline Autopsy & 14/124 (11.3\%) \\
\hline \multicolumn{2}{|l|}{ Tumor location } \\
\hline Right lobe & $60 / 124(48.4 \%)$ \\
\hline Left lobe & $41 / 124(33.1 \%)$ \\
\hline Bi-lobar & $23 / 124(18.5 \%)$ \\
\hline \multicolumn{2}{|l|}{ Tumor Size } \\
\hline Range (cm) & $1.5-27$ \\
\hline Mean $(\mathrm{cm})$ & $9.4(\mathrm{SD} \pm 5.8)$ \\
\hline \multicolumn{2}{|l|}{ Tumor number } \\
\hline Single & $90 / 118(76.3 \%)$ \\
\hline Multiple & 28/118 (23.7\%) \\
\hline \multicolumn{2}{|l|}{ Management } \\
\hline Liver resection & 98/116 (84.5\%) \\
\hline Liver transplant & 3/116 (2.6\%) \\
\hline Chemotherapy & $7 / 116(6.0 \%)$ \\
\hline Transcatherer arterial embolization(TACE) & $5 / 116(4.3 \%)$ \\
\hline Radiofrequency ablation & $1 / 116(0.8 \%)$ \\
\hline \multicolumn{2}{|l|}{ Immunohistochemical stains } \\
\hline Chromogranin A & 90/95 (94.7\%) \\
\hline Synaptophysin & $48 / 95(50.5 \%)$ \\
\hline Cytokeratin & 13/95 (13.7\%) \\
\hline Neuron specific enolase & 46/95 (48.4\%) \\
\hline \multicolumn{2}{|l|}{ Disease free interval (months) } \\
\hline Minimum & 1 \\
\hline Maximum & 180 \\
\hline Mean & 33.6 \\
\hline \multicolumn{2}{|l|}{ Recurrence } \\
\hline Recurrence & 23/116 (19.8\%) \\
\hline No recurrence & $93 / 116(80.2 \%)$ \\
\hline \multicolumn{2}{|l|}{ Survival } \\
\hline Death & $34 / 118(28.8 \%)$ \\
\hline Alive & $84 / 118(71.2 \%)$ \\
\hline \multicolumn{2}{|l|}{ Follow up (months) } \\
\hline Longest survival & $>192$ \\
\hline Shortest survival & $<1$ \\
\hline Mean survival & 41 \\
\hline \multicolumn{2}{|l|}{ Metastases } \\
\hline Metastase & 21/113 (18.6\%) \\
\hline No metastases & $92 / 113(81.4 \%)$ \\
\hline \multicolumn{2}{|l|}{ Survival } \\
\hline 1 year & $82.0 \%$ (CI 0.74-0.89) \\
\hline 5 years & $75.0 \%$ (CI 0.66-0.83) \\
\hline 10 years & $73.4 \%$ (CI 0.64-0.82) \\
\hline
\end{tabular}

*This is based on detail of the individual cases reviewed. 


\section{Patient Selection for Surgery}

Eight years ago, Yao et al provided a standardized algorithm for selecting patient who will benefit from surgical resection and those proposal remains the current benchmark diagnostic tool. Their recommendation was based on four premises: primary or secondary hepatic lesion; extent of associated functional symptoms; intrahepatic and extrahepatic tumor burden, and information about tumor biology if possible [87]. The authors suggested an extensive, meticulous search for extrahepatic lesion before surgical resection is entertained, and if no other primary tumor is found at the time of liver resection, a close follow-up with imaging should continue since it may uncover an occult primary tumor within a few years. In addition, patient with functional symptoms due to tumor byproduct such as carcinoid syndrome should undergo surgical resection before other non-effective adjuvant therapies, and the main contraindication to surgery should be an anticipated incomplete resection except when tumor debulking was the initial surgical intent [87]. Finally, a good knowledge of the tumor biology in-question is very critical in patient selection since NECs are less aggressive with slow disease progression [87].

\section{Other Therapies}

There are several adjuvant therapies being used in the management of PHNETs, however their role and effectiveness is still unknown. Andreola et al reported the case of a 19-year woman who was diagnosed with unresectable carcinoid tumor of the liver with metastases to regional lymph node and common hepatic duct [19]. Systemic chemotherapy with 5-fluorouracil lead to tumor down-staging and subsequent resection. In the same series, two other patients failed to respond to systemic chemotherapy [19]. Approximately 6\% of the cases reviewed were treated with chemotherapy as the main treatment modality [9, $10,19,32,33,59]$. The main use of chemotherapy is for unresectable lesions and tumors with distant metastases $[7-9,18,19,34,56,58]$. So far the paucity of cases makes it difficult to also evaluate the effectiveness of transarterial chemo-embolization (TACE). This modality has been used in downstaging unresectable lesion [40, 45-47, 66, 67], and recurrent tumor post resection [13, 19, 21, 25].

Moreover, the effectiveness of radiofrequency ablation and percutaneous ethanol injection treatment (PEIT) are limited. Huang et al reported the application of PEIT in a patient with three recurring tumors 30 days after resection with good response and disease free interval of 13 months after treatment [25]. Finally, no clear indication for liver transplantation exists, but transplantation has been performed in few patients with unresectable lesion, multiple liver lesion, and large tumor burden with success
$[22,76]$. At the moment, surgical resection seems to be the only effective management available and the treatment of choice $[6,15,18,25,88]$.

\section{Conclusion}

Despite the liver being the common site for metastases from other gastrointestinal NEC or other tumors, primary hepatic neuroendocrine tumors are rear but can occur. PHNETs are slightly common in female, with mean age of 51.9 years, and presents with vague abdominal pain. The tumor has right lobar preference and endocrinologically silent. Diagnosis entails a systematic and painstakingly searches for extrahepatic source using preoperative modalities such ultrasound, CT scan, MRI, PET scan, octreoscan, and endoscopy. Inability to make any preoperative diagnosis or find any extrahepatic lesion is a common scenario and sometimes the only method of diagnosis is effective, close follow-up with imaging after surgical resection. In most cases tumor cells are immunohistochemically positive for CgA. Surgical resection is the treatment of choice and more prospective cases are needed to assess other therapies.

\section{DOD Disclaimer}

The views expressed in this review are those of the author and do not reflect the official policy of the Department of the Navy (DON), Department of Defense (DOD), or US Government.

\section{References}

1. Oberndorfer S: Karzinoide tumoren des dunndarms, Frank Z. Pathol 1907;1:426-429.

2. Modlin IM, Sandor A. An analysis of 8305 cases of carcinoid tumors. Cancer. 1997;79(4):813-829.

3. Maggard MA, O’Connell JB, Ko CY. Updated population-based review of carcinoid tumors. Ann Surg. 2004;240(1):117-122.

4. Godwin JD, 2nd. Carcinoid tumors. An analysis of 2,837 cases. Cancer. 1975;36(2):560-569.

5. Caplin ME, Buscombe JR, Hilson AJ, Jones AL, Watkinson AF, Burroughs AK. Carcinoid tumour. Lancet. 1998;352(9130):799-805.

6. Knox CD, Anderson CD, Lamps LW, Adkins RB, Pinson CW. Long-term survival after resection for primary hepatic carcinoid tumor. Ann Surg Oncol. 2003;10(10):1171-1175.

7. Barsky SH, Linnoila I, Triche TJ, Costa J. Hepatocellular carcinoma with carcinoid features. Hum Pathol. 
1984;15(9):892-894.

8. Hsueh C, Tan XD, Gonzalez-Crussi F. Primary hepatic neuroendocrine carcinoma in a child. Morphologic, immunocytochemical, and molecular biologic studies. Cancer. 1993;71(8):2660-2665.

9. Pilichowska M, Kimura N, Ouchi A, Lin H, Mizuno Y, Nagura H. Primary hepatic carcinoid and neuroendocrine carcinoma: clinicopathological and immunohistochemical study of five cases. Pathol Int. 1999;49(4):318324.

10. Dala R, Shoosmith J, Lilenbaum R, Cabello-Inchausti B. Primary hepatic neuroendocrine carcinoma: an underdiagnosed entity. Ann Diagn Pathol. 2006;10(1):2831.

11. Lin CW, Lai CH, Hsu CC, Hsu CT, Hsieh PM, Hung KC, Chen YS. Primary hepatic carcinoid tumor: a case report and review of the literature. Cases J. 2009;2(1):90.

12. Tohyama T, Matsui K, Kitagawa K. Primary hepatic carcinoid tumor with carcinoid syndrome and carcinoid heart disease: a case report of a patient on long-term follow-up. Intern Med. 2005;44(9):958-962.

13. Iwao M, Nakamuta M, Enjoji M, Kubo H, Fukutomi T, Tanabe Y, Nishi H, et al. Primary hepatic carcinoid tumor: case report and review of 53 cases. Med Sci Monit. 2001;7(4):746-750.

14. Ferrero A, Gallino C, D’Aloisio G, Gandini G, Garavoglia $M$. Primary neuroendocrine carcinoma of the liver: difficult diagnosis of a rare neoplasm. Acta Chir Belg. 1999;99(6):299-302.

15. Donadon M, Torzilli G, Palmisano A, Del Fabbro D, Panizzo V, Maggioni M, Santambrogio R, et al. Liver resection for primary hepatic neuroendocrine tumours: report of three cases and review of the literature. Eur J Surg Oncol. 2006;32(3):325-328.

16. Akahoshi T, Higashi H, Tsuruta S, Tahara K, Matsumoto T, Takeuchi H, Era S, et al. Primary neuroendocrine carcinoma coexisting with hemangioma in the liver: report of a case. Surg Today. 2010;40(2):185-189.

17. Lewis RB, Lattin GE, Jr., Makhlouf HR, Levy AD. Tumors of the liver and intrahepatic bile ducts: radiologicpathologic correlation. Magn Reson Imaging Clin N Am. 2010;18(3):587-609, xii.

18. Hwang S, Lee YJ, Lee SG, Kim CW, Kim KH, Ahn $\mathrm{CS}$, Moon KM, et al. Surgical treatment of primary neuroendocrine tumors of the liver. J Gastrointest Surg. 2008;12(4):725-730.

19. Andreola S, Lombardi L, Audisio RA, Mazzaferro V, Koukouras D, Doci R, Gennari L, et al. A clinicopathologic study of primary hepatic carcinoid tumors. Cancer. 1990;65(5):1211-1218.

20. Yasoshima H, Uematsu K, Sakurai K, Ueno Y, Hori K, Kanazawa N, Tanaka T, et al. Primary hepatic carcinoid tumor. Acta Pathol Jpn. 1993;43(12):783-789.

21. Iimuro Y, Deguchi Y, Ueda Y, Tanaka A, Iwasa Y, Ishihara
M, Mizuta K, et al. Primary hepatic carcinoid tumor with metachronous lymph node metastasis after long-term follow up. J Gastroenterol Hepatol. 2002;17(10):11191124.

22. Fenwick SW, Wyatt JI, Toogood GJ, Lodge JP. Hepatic resection and transplantation for primary carcinoid tumors of the liver. Ann Surg. 2004;239(2):210-219.

23. Fenoglio LM, Severini S, Ferrigno D, Golle G, Serraino C, Bracco C, Castagna E, et al. Primary hepatic carcinoid: a case report and literature review. World J Gastroenterol. 2009;15(19):2418-2422.

24. Takayasu K, Muramatsu Y, Sakamoto M, Mizuguchi Y, Moriyama N, Wakao F, Kosuge T, et al. Findings in primary hepatic carcinoid tumor: US, CT, MRI, and angiography. J Comput Assist Tomogr. 1992;16(1):99-102.

25. Huang YQ, Xu F, Yang JM, Huang B. Primary hepatic neuroendocrine carcinoma: clinical analysis of 11 cases. Hepatobiliary Pancreat Dis Int. 2010;9(1):44-48.

26. Fujino K, Koito K, Sano S, Takahara T, Nakamura E, Morisaki Y, Furuya T, et al. A primary hepatic carcinoid tumor: evaluation by computed tomography and magnetic resonance imaging. Radiat Med. 1998;16(5):371373.

27. van der Hoef M, Crook DW, Marincek B, Weishaupt D. Primary neuroendocrine tumors of the liver: MRI features in two cases. Abdom Imaging. 2004;29(1):77-81.

28. Skagias L, Vasou O, Ntinis A, Kondi-Pafiti A, Koureas A, Politi E. Primary hepatic neuroendocrine tumor with exophytic growth: report of a case with diagnosis by fine needle aspiration biopsy. Acta Cytol. 2010;54(2):202204.

29. Shetty PK, Baliga SV, Balaiah K, Gnana PS. Primary hepatic neuroendocrine tumor: an unusual cystic presentation. Indian J Pathol Microbiol. 2010;53(4):760-762.

30. Mehta DC, Warner RR, Parnes I, Weiss M. An 18-year follow-up of primary hepatic carcinoid with carcinoid syndrome. J Clin Gastroenterol. 1996;23(1):60-62.

31. Ruckert RI, Ruckert JC, Dorffel Y, Rudolph B, Muller JM. Primary hepatic neuroendocrine tumor: successful hepatectomy in two cases and review of the literature. Digestion. 1999;60(2):110-116.

32. Primack A, Wilson J, O’Connor GT, Engelman K, Hull E, Canellos GP. Hepatocellular carcinoma with the carcinoid syndrome. Cancer. 1971;27(5):1182-1189.

33. Ali M, Fayemi AO, Braun EV. Malignant apudoma of the liver with symptomatic intractable hypoglycemia. Cancer. 1978;42(2):686-692.

34. Walter JF, Appelman HD, Reuter SR. Angiographic and pathologic features of probable primary carcinoid-like hepatic tumors. Gastrointest Radiol. 1978;3(4):397-400.

35. Warner TF, Seo IS, Madura JA, Polak JM, Pearse AG. Pancreatic-polypeptide-producing apudoma of the liver. Cancer. 1980;46(5):1146-1151.

36. Gould VE, Banner BF, Baerwaldt M. Neuroendocrine 
neoplasms in unusual primary sites. Diagn Histopathol. 1981;4(3):263-277.

37. Norgaard T, Bardram L. Endocrine liver tumour differential diagnosis from hepatocellular carcinoma. Histopathology. 1985;9(7):777-781.

38. Smith AL, Auldist AW. Successful surgical resection of an hepatic gastrinoma in a child. J Pediatr Gastroenterol Nutr. 1984;3(5):801-804.

39. Xi YP, Yu JY. Primary neuroendocrine carcinoma of the liver. Ultrastruct Pathol. 1986;10(4):331-336.

40. Miura K, Shirasawa H. Primary carcinoid tumor of the liver. Am J Clin Pathol. 1988;89(4):561-564.

41. Sioutos N, Virta S, Kessimian N. Primary hepatic carcinoid tumor. An electron microscopic and immunohistochemical study. Am J Clin Pathol. 1991;95(2):172-175.

42. Aoki K, Sakamoto M, Mukai K, Kosuge T, Takayama T, Hiroshashi S. Signet-ring cell carcinoid: a primary hepatic carcinoid tumor with cytoplasmic inclusions comprising of aggregates of keratin. Jpn J Clin Oncol. 1992;22(1):54-59.

43. Imaoka I, Sugimura K, Tamura K. Case report: MR imaging of a carcinoid tumour of the liver. Clin Radiol. 1993;47(4):287-289.

44. Moriura S, Ikeda S, Hirai M, Naiki K, Fujioka T, Yokochi K, Gotou S. Hepatic gastrinoma. Cancer. 1993;72(5):1547-1550.

45. Krishnamurthy SC, Dutta V, Pai SA, Kane SV, Jagannath P, Desouza LJ, Deshpande R, et al. Primary carcinoid tumor of the liver: report of four resected cases including one with gastrin production. J Surg Oncol. 1996;62(3):218-221.

46. Sano K, Kosuge T, Yamamoto J, Shimada K, Takayama T, Yamasaki S, Makuuchi M. Primary hepatic carcinoid tumors confirmed with long-term follow-up after resection. Hepatogastroenterology. 1999;46(28):2547-2550.

47. Asakawa T, Tomioka T, Abe K, Yamaguchi T, Tsunoda T, Kanematsu T. Primary hepatic carcinoid tumor. J Gastroenterol. 1999;34(1):123-127.

48. Nemes B, Podder H, Jaray J, Dabasi G, Lazar L, Schaff Z, Sotonyi P, Jr., et al. Primary hepatic carcinoid in a renal transplant patient. Pathol Oncol Res. 1999;5(1):6769.

49. Mizuno Y, Ohkohchi N, Fujimori K, Doi H, Orii T, Asakura T, Kimura N, et al. Primary hepatic carcinoid tumor: a case report. Hepatogastroenterology. 2000;47(32):528-530.

50. Kim SR, Imoto S, Maekawa Y, Matsuoka T, Hayashi Y, Ando K, Mita K, et al. CEA producing primary hepatic carcinoid. Hepatol Res. 2002;22(4):313-321.

51. Kaya G, Pasche C, Osterheld MC, Chaubert P, Fontolliet C. Primary neuroendocrine carcinoma of the liver: an autopsy case. Pathol Int. 2001;51(11):874-878.

52. Komatsuda T, Ishida H, Furukawa K, Miyauchi T, Heianna J. Primary carcinoid tumor of the liver: report of a case with an emphasis on contrast-enhanced ultrasonographic findings. J Clin Ultrasound. 2005;33(6):302304.

53. Kohashi T, Itamoto T, Katayama K, Nakahara H, Onoe T, Matsugu Y, Nakatsuka H, et al. Primary hepatic carcinoid tumor (a case report). Hepatogastroenterology. 2005;52(64):1218-1220.

54. Abdel Wahab M, Fathy O, Elghwalby N, Sultan A, Mostafa M, El-Baz M, Elsaadany M, et al. Primary hepatic carcinoid tumor: one Egyptian center experience. Hepatogastroenterology. 2006;53(67):33-38.

55. Tsuchimochi S, Nakajo M, Inoue H, Miyazono N, Noguchi I, Matsushita T, Senba I, et al. Primary hepatic neuroendocrine carcinoma with multiple metastases: a case report. Radiat Med. 1995;13(4):183-185.

56. Fukunaga M. Neuroendocrine carcinoma of the liver: an autopsy case. Pathol Int. 1998;48(6):481-485.

57. Ishida M, Seki K, Tatsuzawa A, Katayama K, Hirose K, Azuma T, Imamura Y, et al. Primary hepatic neuroendocrine carcinoma coexisting with hepatocellular carcinoma in hepatitis C liver cirrhosis: report of a case. Surg Today. 2003;33(3):214-218.

58. Garcia MT, Bejarano PA, Yssa M, Buitrago E, Livingstone A. Tumor of the liver (hepatocellular and high grade neuroendocrine carcinoma): a case report and review of the literature. Virchows Arch. 2006;449(3):376381.

59. Yasuda E, Takeshita A, Murata S, Ihaku Y, Nitta T, Akutagawa H, Egashira Y, et al. Neuroendocrine carcinoma of the liver associated with dermatomyositis: autopsy case and review of the literature. Pathol Int. 2006;56(12):749-754.

60. Wang CY, Chen A, Tseng HH, Tu YC, Chen VT, Hsieh HF. Carcinoid tumor localized in the liver--two cases report: immunohistochemical and ultrastructural studies. Zhonghua Yi Xue Za Zhi (Taipei). 1992;49(5):365-372.

61. Yamashita Y, Takahashi M, Tsuji A, Korogi Y, Uozumi H, Kimura Y. Primary carcinoid tumor of the liver: a case report. J Comput Tomogr. 1986;10(4):313-317.

62. Une Y, Li Y, Uemura K, Kamiyama T, Shimamura T, Uchino J, Nojima T. Primary hepatic carcinoid tumor. Oncol Rep. 1996;3(6):1091-1095.

63. Ishizu A, Yokoyama K, Yoshiki T. Primary neuroendocrine carcinoma of the liver diagnosed at autopsy. J Gastroenterol Hepatol. 2003;18(8):1002-1004.

64. Oh YH, Kang GH, Kim OJ. Primary hepatic carcinoid tumor with a paranuclear clear zone: a case report. J Korean Med Sci. 1998;13(3):317-320.

65. Schwartz G, Colanta A, Gaetz H, Olichney J, Attiyeh F. Primary carcinoid tumors of the liver. World J Surg Oncol. 2008;6(91.

66. Touloumis Z, Delis SG, Triantopoulou C, Giannakou N, Avgerinos C, Dervenis C. Primary hepatic carcinoid; a diagnostic dilemma: a case report. Cases J. 
2008;1(1):314.

67. Lau PP, Tint KA, Tse GM, Lui PC. Primary hepatic carcinoid tumours: report of two cases. Pathology. 2006;38(5):458-461.

68. Holgado-Galicia MV, Nomorosa KM, Ang EL, LantionAng FL. Primary carcinoid tumour of the liver in a young Filipino female. BMJ Case Reports 2011;1(1):3319.

69. Tazi EM, Essadi I, M’rabti H, Errihani H. Hepatocellular carcinoma and high grade neuroendocrine carcinoma: A case report and review of the literature. World J of Oncol 2011;2(1):37.40.

70. Yokoigawa N, Kitade H, Ohishi M, Ozaki T, Miyaso T, Okazaki S, Nakai K, et al. Surgical Control of a Primary Hepatic Carcinoid Tumor: A Case Report. Case Rep Gastroenterol. 2009;3(1):30-35.

71. Bastaki W, Mothaffer F, Varro J, Al-Ghanim M, Malak L, Ayyash E, Asafar S. Primary hepatic carcinoid tumor: A case report. Med Princ Pract 2005;14(4):288-291.

72. Zanconati F, Falconieri G, Lamovec J, Zidar A. Small cell carcinoma of the liver: a hitherto unreported variant of hepatocellular carcinoma. Histopathology. 1996;29(5):449-453.

73. Rehman A, Pirzada MT, Manzar S. Neuroendocrine tumour of liver: A case report. Pakistan J of Surg 2008;24(1):71-73.

74. Shah NA, Urusova IA, D’Agnolo A, Colquhoun SD, Rosenbloom BE, Vener SL, Geller SA, et al. Primary hepatic carcinoid tumor presenting as Cushing's syndrome. J Endocrinol Invest. 2007;30(4):327-333.

75. Foley DS, Sunil I, Debski R, Ignacio RC, Nagaraj HS. Primary hepatic carcinoid tumor in children. J Pediatr Surg. 2008;43(11):e25-28.

76. de Liguori Carino N, Manzia TM, Tariciotti L, Berlanda M, Orlando G, Tisone G. Liver transplantation in primary hepatic carcinoid tumor: case report and literature review. Transplant Proc. 2009;41(4):1386-1389.

77. Alpert LI, Zak FG, Werthamer S, Bochetto JF. Cholangiocarcinoma: a clinicopathologic study of five cases with ultrastructural observations. Hum Pathol. 1974;5(6):709-728.

78. Brown WM, 3rd, Henderson JM, Kennedy JC. Carcinoid tumor of the bile duct. A case report and literature review. Am Surg. 1990;56(6):343-346.

79. Solcia E, Kloeppel G, Sobin LH: WHO histological typing of endocrine tumors. 2nd ed. New York: SpringerVerlag, 2000.

80. Yao JC, Hassan M, Phan A, Dagohoy C, Leary C, Mares JE, Abdalla EK, et al. One hundred years after "carcinoid”: epidemiology of and prognostic factors for neuroendocrine tumors in 35,825 cases in the United States. J Clin Oncol. 2008;26(18):3063-3072.

81. Nikfarjam M, Muralidharan V, Christophi C. Primary hepatic carcinoid tumours. HPB (Oxford). 2004;6(1):13-17.

82. Gravante G, De Liguori Carino N, Overton J, Manzia TM, Orlando G. Primary carcinoids of the liver: a review of symptoms, diagnosis and treatments. Dig Surg. 2008;25(5):364-368.

83. Chamberlain RS, Canes D, Brown KT, Saltz L, Jarnagin W, Fong Y, Blumgart LH. Hepatic neuroendocrine metastases: does intervention alter outcomes? J Am Coll Surg. 2000;190(4):432-445.

84. Orlefors H, Sundin A, Garske U, Juhlin C, Oberg K, Skogseid B, Langstrom B, et al. Whole-body (11)C-5hydroxytryptophan positron emission tomography as a universal imaging technique for neuroendocrine tumors: comparison with somatostatin receptor scintigraphy and computed tomography. J Clin Endocrinol Metab. 2005;90(6):3392-3400.

85. Oberg K, Eriksson B. Nuclear medicine in the detection, staging and treatment of gastrointestinal carcinoid tumours. Best Pract Res Clin Endocrinol Metab. 2005;19(2):265-276.

86. Chatal JF, Le Bodic MF, Kraeber-Bodere F, Rousseau C, Resche I. Nuclear medicine applications for neuroendocrine tumors. World J Surg. 2000;24(11):1285-1289.

87. Yao JC, Vauthey JN. Primary and metastatic hepatic carcinoid: is there an algorithm? Ann Surg Oncol. 2003;10(10):1133-1135.

88. Soga J. Primary hepatic endocrinomas (carcinoids and variant neoplasms). A statistical evaluation of 126 reported cases. J Exp Clin Cancer Res. 2002;21(4):457468. 